\title{
Estudo do rendimento de bombeamento para um protótipo de carneiro hidráulico de PVC
}

Gustavo EijiYkeda ${ }^{1}$

Fernando da Silva Barbosa²

Miguel Angel Isaac Toledo del Pino 3

\section{Resumo}

Devido à dificuldade energética no meio rural e à necessidade de irrigação, mesmo em pequenas propriedades, tem aumentado o uso do carneiro hidráulico, o qual por meio do princípio do golpe de aríete bombeia água sem o uso de energia elétrica. Contudo, seu rendimento em função da altura bombeada não é tão eficiente. Por meio deste estudo, objetivou-se com a adição de uma válvula retentora na entrada do carneiro ter um ganho de eficiência. A válvula tem a função de formar uma barreira física para a água que retorna, após seu golpe, com a válvula de sucção. 0 projeto foi desenvolvido com delineamento em blocos casualisados, com 4 blocos. Foram instalados 1 carneiro hidráulico de PVC (convencional) e 1 carneiro hidráulico com retentor que foram avaliados ao mesmo tempo. A altura de queda foi a mesma, variando 1 metro da altura bombeada a cada 4 dias. Foram realizadas 4 repetições para cada altura analisada e avaliou-se a vazão de saída por meio de hidrômetros, pressão de entrada e saída do sistema, vazão de entrada, volume de água perdida e número de batidas por minuto, sendo possível medir sua eficiência. O carneiro hidráulico com válvula apresentou um rendimento inferior na maioria das alturas estudadas, o bombeamento foi superior ao convencional somente aos 9 metros de altura, o que prejudica a relação custo-benefício.

Palavras-chave: Golpe de Aríete. Eficiência de bombeamento. Válvula de retenção. Choque de Aríete.

\section{Introdução}

Com a busca por energias alternativas para substituir a energia elétrica ou combustíveis fósseis, o carneiro hidráulico, que no passado foi muito utilizado, voltou a ser procurado. Por seu fácil manuseio, o aparelho não demanda uma mão de obra especializada para sua utilização, manutenção ou energia elétrica, seu funcionamento não emite gases poluentes e o custo de manutenção e operação são relativamente baixos (ABATE, 2000).

O carneiro é um dispositivo que foi usado extensivamente por quase um século em áreas rurais para bombear água para alturas superiores a 100 metros. É a máquina ideal para bombeamento se certas condições forem ideais, pois o sistema somente funciona com a força da água em queda

1 Instituto Federal de Educação, Ciência e Tecnologia do Sul de Minas Gerais, Campus Inconfidentes, discente do curso superior de Engenharia Agronômica. gustavo.e.ykeda@gmail.com. Rua Rio de Janeiro, 37, Atibaia (SP), CEP: 12942-270.

2 Instituto Federal de Educação, Ciência e Tecnologia do Sul de Minas Gerais, Campus Inconfidentes, professor EBTT. fernando.barbosa@ifsuldeminas.edu.br.

3 Instituto Federal de Educação, Ciência e Tecnologia do Sul de Minas Gerais, Campus Inconfidentes, professor EBTT miguel.toledo@ifsuldeminas.edu.br. 
direcionada por um tubo. O sistema é automático e tem um excepcional histórico de ausência de problemas (WATT, 1975).

Para funcionar o carneiro hidráulico deve ser instalado em um nível mais baixo do que a fonte de água, no mínimo 1,0 m e, de preferência, na cota mais baixa possível (AZEVEDO NETO et al., 1998). Azevedo Neto et al. (1998) resumem o funcionamento do aparelho indicando que inicialmente a água que chega ao carneiro hidráulico sai por uma válvula externa até o momento em que atinge uma velocidade elevada, neste instante a válvula se fecha repentinamente, ocasionando uma sobre pressão no interior do aparelho, chamado golpe de aríete, que possibilita o bombeamento da água.

O "golpe de aríete" é o efeito da interrupção abrupta de um escoamento contínuo do fluxo da água em uma tubulação que resulta em um aumento de pressão; esse efeito pode ser observado ao fechar bruscamente a saída de água de uma mangueira, o que causa um movimento independente da mangueira (TIAGO FILHO, 2002). A sobrepressão pode atingir grandes proporções, provocando ruptura e grandes prejuízos quando não é controlada, porém o carneiro hidráulico utiliza essa sobrepressão para recalcar a água de um reservatório até um ponto com cota superior (CARVALHO; OLIVEIRA, 2008).

Para o carneiro protótipo teorizou-se que após a interrupção abrupta da água há uma energia potencial gerada dentro do carneiro hidráulico, essa energia faz com que a água seja impulsionada para uma cota superior (CARVALHO; OLIVEIRA, 2008), porém há uma perda de energia durante esse processo, pois parte dessa energia é dissipada quando ocorre o encontro da água que sofreu o golpe com a água que entra novamente no sistema do carneiro hidráulico. A inclusão de uma barreira física, como a adição de um retentor horizontal ao "te" inferior do equipamento, pode minimizar essa dissipação de energia.

Neste sentido, o objetivo deste trabalho foi avaliar o efeito da inclusão de uma segunda válvula de retenção em um sistema de bombeamento do tipo "carneiro hidráulico de PVC" (Protótipo) quando comparado a um sistema "carneiro hidráulico de PVC (Original)" tendo como hipótese que ocorreria um aumento do rendimento em altura (altura de bombeamento) e que o material construtivo resistiria ao aumento de pressão interna melhorando a relação custo-benefício.

\section{Material e métodos}

O estudo foi conduzido na Fazenda-Escola do Instituto Federal de Educação, Ciência e Tecnologia do Sul de Minas Gerais, Campus Inconfidentes, utilizando como fonte de água um reservatório/ tanque já construído e situado próximo ao viveiro de mudas da instituição com as coordenadas geográficas: Latitude $22^{\circ} 18^{\prime} 42.05^{\prime \prime S}$, Longitude 46²0'1.63"O. Foi realizada uma análise do perfil topográfico do local de estudo a fim de mensurar a altura de trabalho em que foram instalados os carneiros hidráulicos, chegando a um desnível máximo de 5 metros.

$O$ delineamento experimental adotado foi o Delineamento em Blocos Casualizados (DBC) em esquema fatorial $2 \times 4$, sendo 2 sistemas de bombeamento (S) e 4 alturas de bombeamento (A) testados em 4 repetições (TABELA 2). Os sistemas avaliados foram: "carneiro hidráulico de PVC com válvula adicional" (Protótipo); "carneiro hidráulico de PVC sem válvula adicional" (Convencional)". A vazão disponível no local foi de $0,7 \mathrm{~L} \mathrm{~s}^{-1}$ e o tempo de funcionamento do carneiro foi de 8 horas diárias.

As variáveis estudadas foram: (1) Pressão na entrada do sistema com o carneiro em funcionamento, em mca; (2) Pressão de bombeamento na saída do sistema em funcionamento, em mca; (3) 
Vazão bombeada, em L h-1; (4) Número de batidas, em Batidas minuto-1; (5) Rendimento econômico, em $L$ dia $^{-1}$ real $^{-1}$.

Para calcular o rendimento econômico utilizou-se da equação apresentada a seguir:

$$
\mathrm{RE}=\frac{\text { Vazão bombeada }}{\text { Custo do carneiro }}
$$

Em que:

Vazão Bombeada em L dia-1;

Custo do carneiro em reais (Custo do carneiro de PVC $=\mathrm{R} \$ 110,00$;

Custo do carneiro protótipo $=\mathrm{R} \$ 163,00$

A montagem do carneiro hidráulico seguiu o modelo apresentado na revista Globo Rural de 14 de maio de 2015 (FIGURA 1)

Figura 1. Detalhe do esquema de acoplamento das peças para o carneiro hidráulico de PVC (Convencional)

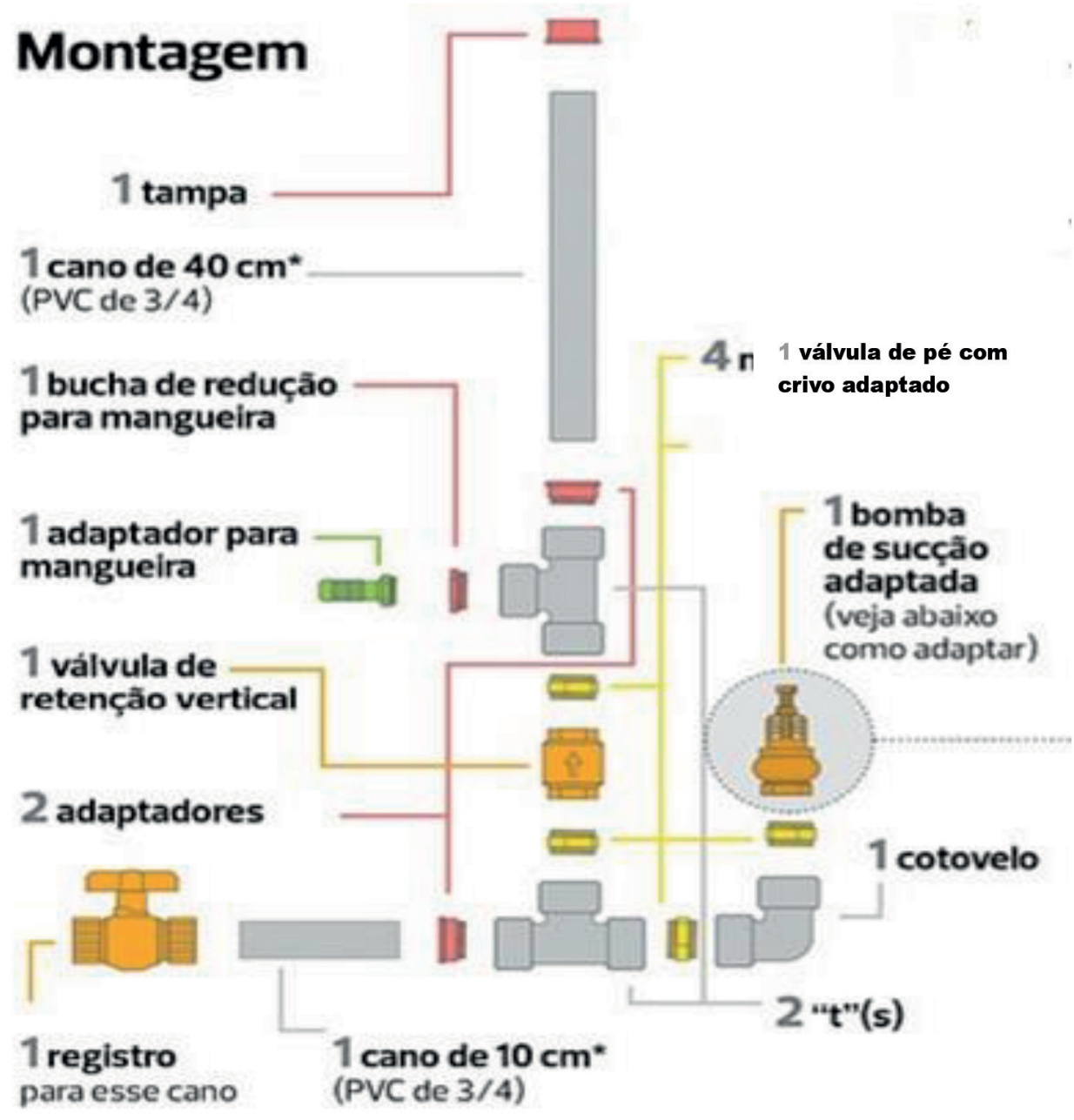

Fonte: Adaptado de GLOBO RURAL (2015). 
No protótipo foi utilizado o mesmo conjunto de peças da construção do carneiro hidráulico de PVC (Convencional), contudo foi necessário adicionar 2 niples de 3/4" e 1 retentor vertical de 3/4". As peças foram incluídas no ponto de destaque no esquema abaixo (FIGURA 2).

Figura 2. Detalhe do esquema de acoplamento das peças para o carneiro hidráulico de PVC (Protótipo)

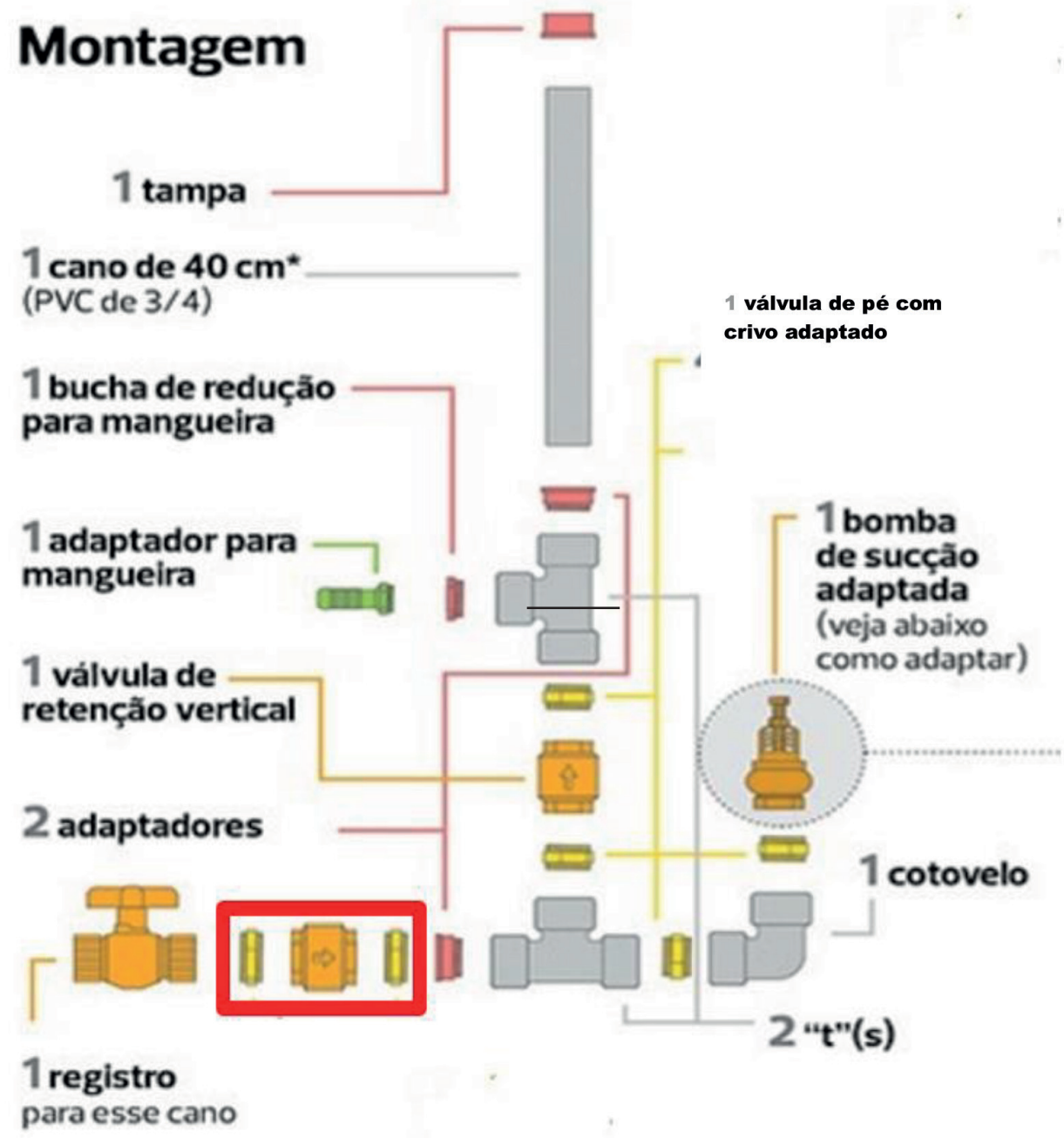

Fonte: Adaptado de GLOBO RURAL (2015).

Para realizar as medições das pressões foi necessário construir um adaptador de manômetro. Foi utilizado 1 conector tipo "T" com 2 entradas de mangueira de diâmetro 1 " e outro "T" de 1/2" e 1 saída com rosca "fêmea" de diâmetro 1" e outro de 1/2", 1 adaptador de diâmetro 1" e outro de 1/2". Aproximadamente $5 \mathrm{~cm}$ de tubo de PVC de 1" e outro de 1/2", 1 CAP de 1 " e outro de $1 / 2$ " e 1 bico de câmara de ar para realizar a leitura. Para realizar a medida de pressão foi utilizado um calibrador de pneu tipo caneta (FIGURA 4).

Foi construído um adaptador para manômetro de 1" para medir a pressão na entrada do carneiro e um adaptador para manômetro de 1/2" para medir a pressão na saída/recalque do sistema. 
Foi instalado um filtro utilizando uma caixa de madeira onde foram fixadas as mangueiras de sucção. Como elemento filtrante foram utilizados 2 sacos de juta sobrepostos para reter as impurezas físicas e efetuar a filtragem da água.

Para alimentação do carneiro (sucção), foram utilizados 25 metros de mangueira de polietileno de 1 polegada, sendo alimentação individual para cada carneiro. Para as mangueiras de saída (adutora), foram utilizados 20 metros de mangueiras de polietileno de 1/2 polegada, sendo a saída individual para cada carneiro. Foi instalado na saída dos carneiros um Hidrômetro Unimag - monojato Classe B com diâmetro nominal de $1 / 2$ " - 3/4" para cada sistema com o propósito de mensurar 0 volume de água bombeado durante o período de estudo.

Com o auxílio de uma corda graduada de metro em metro, que foi fixada no suporte de suspensão e em um galho de aproximadamente $12 \mathrm{~m}$ de altura, elevaram-se as mangueiras nas alturas desejadas.

Para avaliação dos sistemas foi mantida a altura de sucção fixa $(5,0 \mathrm{~m})$, variando as alturas de recalque de metro em metro até o nível máximo de 11 metros de altura (TABELA 1).

Tabela 1. Alturas de bombeamento avaliadas.

\begin{tabular}{cc}
\hline Altura de sucção & Altura de recalque \\
\hline & $8,0 \mathrm{~m}$ \\
Altura fixa $5,0 \mathrm{~m}$ & $9,0 \mathrm{~m}$ \\
& $10,0 \mathrm{~m}$ \\
& $11,0 \mathrm{~m}$ \\
\hline
\end{tabular}

Fonte: Elaborada pelos autores (2017).

Seguindo as alturas avaliadas apresentadas na Tabela 3, foram feitas as avaliações com repetições conforme a Tabela 2, correspondendo cada repetição a um dia de avaliação. 0 tempo de funcionamento e avaliação foi de aproximadamente 8 horas diárias, iniciando às $8 \mathrm{~h}$ e finalizando às 16 h de cada dia.

Tabela 2. Distribuição das repetições/blocos durante o experimento.

\begin{tabular}{lcccc}
\hline \multirow{2}{*}{ Repetição } & \multicolumn{4}{c}{ Altura } \\
\cline { 2 - 5 } & $\mathbf{8 , 0 ~} \mathbf{m}$ & $\mathbf{9 , 0} \mathbf{~ m}$ & $\mathbf{1 0 , 0} \mathbf{~ m}$ & $\mathbf{1 1 , 0 ~} \mathbf{~}$ \\
\hline 1 & $19 / 01 / 2017$ & $23 / 01 / 2017$ & $27 / 01 / 2017$ & $31 / 01 / 2017$ \\
2 & $20 / 01 / 2017$ & $24 / 01 / 2017$ & $28 / 01 / 2017$ & $01 / 02 / 2017$ \\
3 & $21 / 01 / 2017$ & $25 / 01 / 2017$ & $29 / 01 / 2017$ & $02 / 02 / 2017$ \\
4 & $22 / 01 / 2017$ & $26 / 01 / 2017$ & $30 / 01 / 2017$ & $03 / 02 / 2017$ \\
\hline
\end{tabular}

Fonte: Elaborada pelos autores (2017).

Para análise dos resultados foi utilizado o software SISVAR (FERREIRA, 2014), sendo a análise de variância realizada pelo Teste F; para a comparação de médias, aplicou-se o Teste de Scott- Knott, com $5 \%$ de nível de significância. 


\section{Resultados e discussão}

Na Tabela 3 está representado o resumo da análise de variância dos fatores relacionados à pressão e volume que foram avaliados durante este período.

Tabela 3. Resumo da análise de variância nas variáveis, sendo Pressão com o carneiro em funcionamento (PCF) em mca; Pressão de bombeamento na saída do carneiro (PBS) em mca; Vazão bombeada (VB) em L $\mathrm{h}^{-1}$; número de batidas por minuto $\left(B \mathrm{~min}^{-1}\right)$ em Batidas minuto ${ }^{-1}$; rendimento econômico $(\mathrm{RE})$ em $\left(\mathrm{L} \mathrm{s}^{-1}\right) / \mathrm{R} \$$.

\begin{tabular}{lccccc}
\hline Fontes de Variação & PCF & PBS & VB & B min $^{-1}$ & RE \\
\hline Bloco & $0,641^{\text {ns }}$ & $2,326^{\text {ns }}$ & $0,469^{\text {ns }}$ & $1,130^{\text {ns }}$ & $0,324^{\text {ns }}$ \\
Altura (A) & $14,89^{* *}$ & $39,509^{* *}$ & $22,419^{* *}$ & $13,373^{* *}$ & $16,897^{* *}$ \\
Tratamento (T) & $4,841^{*}$ & $53,182^{* *}$ & $0,005^{\text {ns }}$ & $3,225^{\text {ns }}$ & $33,533^{* *}$ \\
A x T & $1,668^{\text {ns }}$ & $0,0031^{*}$ & $3,330^{*}$ & $2,750^{\text {ns }}$ & $1,883^{\text {ns }}$ \\
CV(\%) & 6,28 & 4,46 & 16,97 & 5,25 & 18,77 \\
Média Geral & 13,957 & 15,987 & 95,064 & 43,135 & 0,723 \\
\hline
\end{tabular}

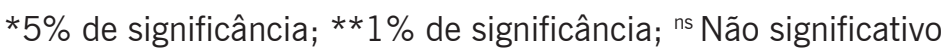

Fonte: Elaborada pelos autores (2017).

Em relação à variável PCF, nota-se na Tabela 3 que houve diferença significativa tanto para Altura quanto para Tratamento, com 1 e 5 \% de significância, respectivamente. Observando a Tabela 4, as alturas de 10 e 11 metros apresentaram maior pressão, tal resultado já era esperado, visto que para bombear em maior altura é necessária maior pressão. Observa-se com a Tabela 5 e o gráfico (FIGURA 3) uma maior pressão de saída no carneiro padrão. A variável PCF do carneiro protótipo foi menor, como esperado, visto que a válvula de retenção horizontal reteria parte dessa pressão causando uma perda localizada de carga.

Tabela 4. Dados médios de pressão na entrada do carneiro em funcionamento (PCF) para as 4 alturas de bombeamento avaliadas, em mca.

\begin{tabular}{cl}
\hline Tratamentos & Médias \\
\hline $8,0 \mathrm{~m}$ & $13,17 \mathrm{~b}$ \\
$9,0 \mathrm{~m}$ & $12,78 \mathrm{~b}$ \\
$10,0 \mathrm{~m}$ & $14,51 \mathrm{a}$ \\
$11,0 \mathrm{~m}$ & $15,36 \mathrm{a}$ \\
\hline
\end{tabular}

Médias seguidas de letras distintas minúsculas na coluna diferem entre si pelo Teste de Scott-Knott $(P<0,05)$.

Fonte: Elaborada pelos autores (2017).

Tabela 5. Dados médios de pressão na entrada do carneiro em funcionamento (PCF) para os 2 carneiros avaliados, em mca.

\begin{tabular}{cc}
\hline Tratamento & Média \\
\hline Protótipo & $13,61 \mathrm{~b}$ \\
Padrão & $14,29 \mathrm{a}$ \\
\hline
\end{tabular}

Médias seguidas de letras distintas minúsculas na coluna diferem entre si pelo Teste de Scott-Knott $(P<0,05)$ Fonte: Elaborada pelos autores (2017). 
Figura 3. Gráfico de pressão na entrada do carneiro em funcionamento (PCF) em função da Altura de bombeamento para os dois equipamentos.

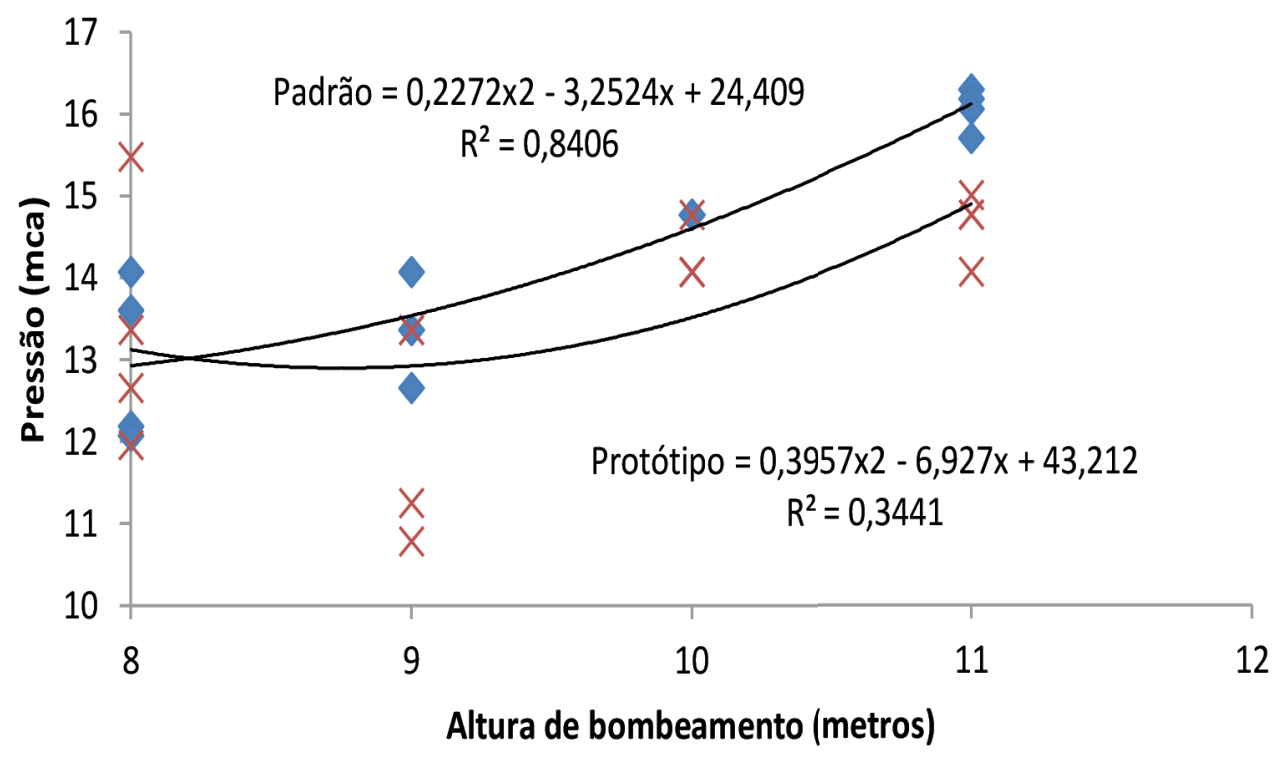

- Padrao $\times$ prototipo — Polinomial (Padrao) — Polinomial (prototipo)

Fonte: Elaborada pelos autores (2017).

Para a variável PBS houve diferença para Altura e Tratamento com interação significativa a nível de $1 \%$ de significância (TABELA 3). Analisa-se pela Tabela 6, assim como no gráfico (FIGURA 4), que o carneiro padrão obteve uma melhor resposta, sendo superior em quase todas as alturas analisadas, somente na altura de 8 metros não se obteve diferença significativa. Esperava-se que a pressão de saída do carneiro protótipo fosse superior e que a válvula de retenção horizontal redirecionaria a pressão do golpe de aríete na entrada do carneiro para a saída, fato que não se concretizou com a condução do experimento.

Tabela 6. Dados médios da interação entre Altura e Tratamento para a variável pressão de bombeamento na saída do carneiro (PBS) em mca.

\begin{tabular}{ccccc}
\hline Tratamento & ----- Médias---- & $\mathbf{9 . 0 ~} \mathbf{m}$ & $\mathbf{1 0 . 0 ~} \mathbf{~}$ & $\mathbf{1 1 . 0 ~ m}$ \\
\hline & $\mathbf{8 , 0 m}$ & $\mathbf{9 , 0 m}$ & $\mathbf{1 0 , 0 m}$ & $\mathbf{1 1 , 0 m}$ \\
Protótipo & $14,422708 \mathrm{Ba}$ & $14,422705 \mathrm{Bb}$ & $14,774480 \mathrm{Bb}$ & $16,650603 \mathrm{Ab}$ \\
\hline Padrão & $14,803793 \mathrm{Ca}$ & $15,595285 \mathrm{Ca}$ & $17,588670 \mathrm{Ba}$ & $19,640678 \mathrm{Aa}$ \\
\hline
\end{tabular}

Médias seguidas de letras distintas maiúsculas na linha e minúsculas na coluna diferem entre si pelo teste de Scott-Knott $(P<0,05)$.

Fonte: Elaborada pelos autores (2017). 
Figura 4. Gráfico de pressão de bombeamento na saída do carneiro (PBS) em função da Altura de bombeamento para os dois equipamentos.

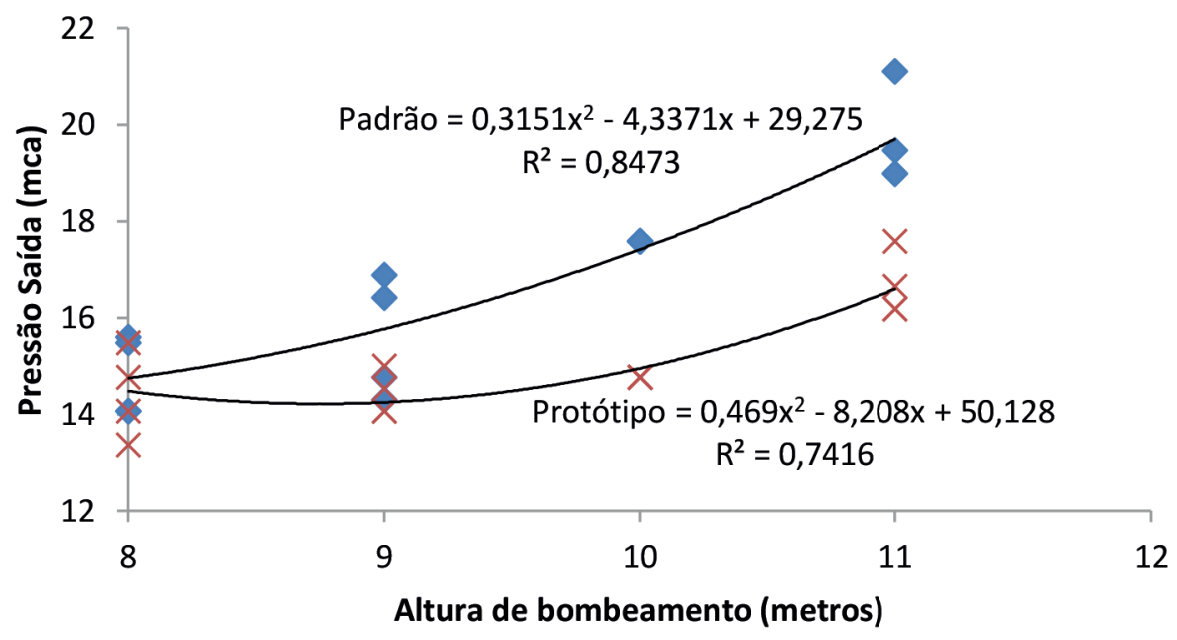

- Padrao $\times$ Prototipo — Polinomial (Padrao) — Polinomial (Prototipo)

Fonte: Elaborada pelos autores (2017).

A variável VB resultou em diferença significativa para Altura com 1 \% de significância, apresentando interação significativa com Tratamento (TABELA 3). Observa-se pela Tabela 7 que o carneiro protótipo obteve uma vazão superior na altura 9 metros. A frequência de batida do carneiro está diretamente relacionada ao desempenho de bombeamento, como são 2 carneiros diferentes, a frequência de batida de um carneiro pode não ser a condição ideal do outro, explicando um melhor rendimento do carneiro protótipo na altura 9,0 metros, em que a frequência de batidas de 44 B min-1(TABELA 8) pode ser uma condição mais favorável, se comparado ao carneiro padrão. 0 inverso também pode ser afirmado, podendo o carneiro protótipo ter trabalhado em outras alturas em condições mais desfavoráveis. Portanto, deve-se realizar um estudo para encontrar as melhores frequências de batidas em cada carneiro e assim fazê-los funcionar em sua máxima eficiência, diferentemente deste estudo em que o objetivo foi manter os 2 carneiros com frequência de batidas parecidas.

Tem-se na Tabela 7 o volume bombeado inferior ao observado por Cararo et al. (2007), que em seu estudo em altura de recalque de 10,0 m observou um bombeamento de recalque mínimo de 115,2 L h-1 e máximo de 481,2 L h-1, porém a tubulação de sucção utilizada em seu experimento foi de aço galvanizado de $50 \mathrm{~mm}$ a 4,37 metros de desnível, no estudo de Abate e Botrel (2000) a tubulação de aço na altura 4,7 metros obteve um rendimento superior. Neste presente estudo foi utilizado tubulação de sucção de polietileno, portanto já era esperado um volume bombeado inferior.

Observa-se no gráfico (FIGURA 5) uma queda de vazão mais acentuada no carneiro protótipo conforme ocorreu o aumento na altura de bombeamento. 
Tabela 7. Dados médios da interação entre Altura e Tratamento para a variável vazão bombeada (VB) em L/h.

\begin{tabular}{ccccc}
\hline \multirow{2}{*}{ Tratamento } & \multicolumn{4}{c}{-----Médias----- } \\
\cline { 2 - 5 } & $\mathbf{8 , 0 m}$ & $\mathbf{9 , 0 m}$ & $\mathbf{1 0 , 0 m}$ & $\mathbf{1 1 , 0 m}$ \\
\hline Protótipo & $125,59 \mathrm{Aa}$ & $122,39 \mathrm{Aa}$ & $75,02 \mathrm{Ba}$ & $58,02 \mathrm{Ba}$ \\
Padrão & $127,623 \mathrm{Aa}$ & $92,25 \mathrm{Bb}$ & $84,13 \mathrm{Ba}$ & $75,46 \mathrm{Ba}$ \\
\hline
\end{tabular}

Médias seguidas de letras distintas maiúsculas na linha e minúsculas na coluna diferem entre si pelo Teste de Scott-Knott $(P<0,05)$

Fonte: Elaborada pelos autores (2017).

Figura 5. Gráfico de vazão bombeada (VB) em função da Altura de bombeamento para os dois equipamentos.

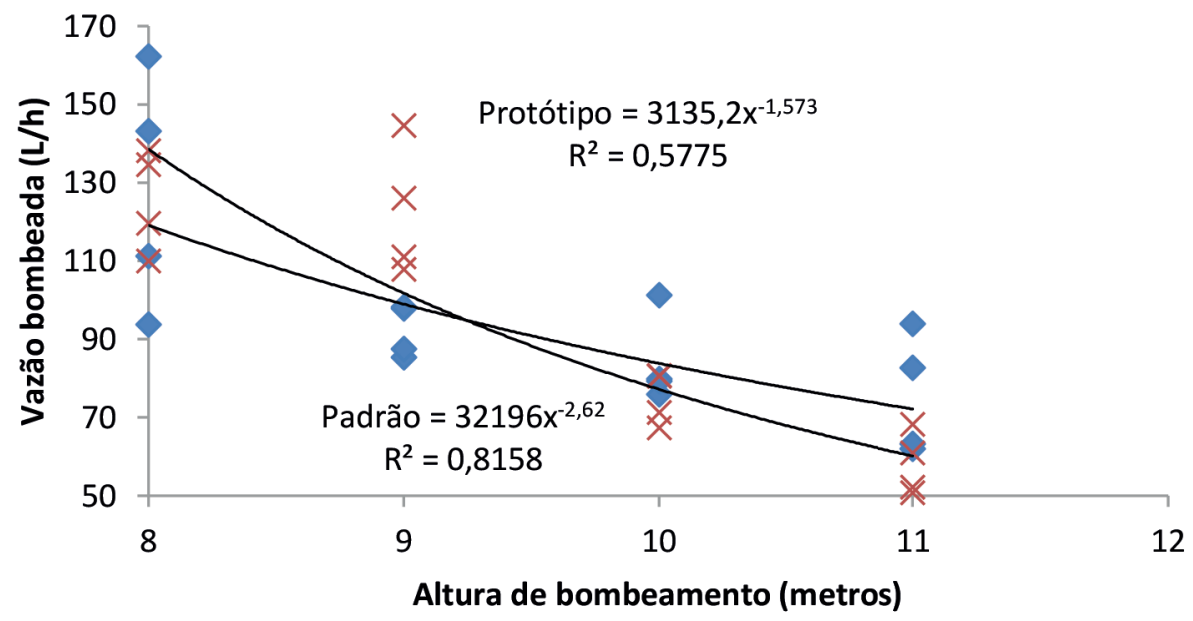

- Padrao $\times$ Prototipo — Potência (Padrao) — Potência (Prototipo)

Fonte: Elaborada pelos autores (2017).

A variável B min-1 resultou em diferença significativa para Altura com 1 \% de significância (TABELA 3). No estudo de Cararo et al. (2007), a frequência de batidas em geral acima de 60 Batidas min $^{-1}$ pode ter influenciado a maior vazão bombeada, além da tubulação de aço galvanizado.

Tabela 8. Dados médios de número de batidas por minuto para as 4 alturas de bombeamento avaliadas em Bat $\min ^{-1}$.

\begin{tabular}{cc}
\hline Tratamentos & Médias \\
\hline $8,0 \mathrm{~m}$ & $45,87 \mathrm{a}$ \\
$9,0 \mathrm{~m}$ & $44,87 \mathrm{a}$ \\
$10,0 \mathrm{~m}$ & $39,29 \mathrm{c}$ \\
$11,0 \mathrm{~m}$ & $42,50 \mathrm{~b}$ \\
\hline
\end{tabular}

Médias seguidas de letras distintas minúsculas na coluna diferem entre si pelo teste de Scott-Knott $(P<0,05)$

Fonte: Elaborada pelos autores (2017). 
Por fim, analisando a questão econômica, o rendimento econômico (RE) diferenciou significativamente tanto para altura quanto para tratamento com nível de $1 \%$ de significância sem apresentar interação entre as fontes de variação (TABELA 3). Observa-se na Tabela 9 e gráfico (FIGURA 6) que o rendimento econômico é superior nos dois carneiros quando aplicada a altura de 8 metros, devido, principalmente, ao volume bombeado nessa altura ter sido superior quando comparado aos demais. O carneiro protótipo por ter um custo maior em função da válvula adicional e por não apresentar maior eficiência de bombeamento resultou em uma relação custo/benefício desfavorável quando comparado com o carneiro padrão (TABELA 10).

Tabela 9. Dados médios de rendimento econômico (RE) para as 4 alturas de bombeamento avaliadas em ( $\mathrm{L}$ $\left.\mathrm{dia}^{-1}\right) / \mathrm{R} \$$.

\begin{tabular}{cc}
\hline Treatment & Mean \\
\hline 8 & $0.965354 \mathrm{a}$ \\
9 & $0.794751 \mathrm{~b}$ \\
10 & $0.612591 \mathrm{c}$ \\
11 & $0.521010 \mathrm{c}$ \\
\hline
\end{tabular}

Médias seguidas de letras distintas minúsculas na coluna diferem entre si pelo Teste de Scott-Knott $(P<0,05)$

Fonte: Elaborada pelos autores (2017).

Tabela 10. Dados médios de rendimento econômico (RE) para os 2 carneiros avaliados em $\left(L \operatorname{dia}^{-1}\right) / R \$$.

\begin{tabular}{cc}
\hline Tratamento & Média \\
\hline Protótipo & $0,584401 \mathrm{~b}$ \\
Padrão & $0,862452 \mathrm{a}$ \\
\hline
\end{tabular}

Médias seguidas de letras distintas minúsculas na coluna diferem entre si pelo Teste de Scott-Knott $(P<0,05)$

Fonte: Elaborada pelos autores (2017).

Figura 6. Gráfico de Rendimento Econômico (\%) em função da Altura de bombeamento para os dois equipamentos.

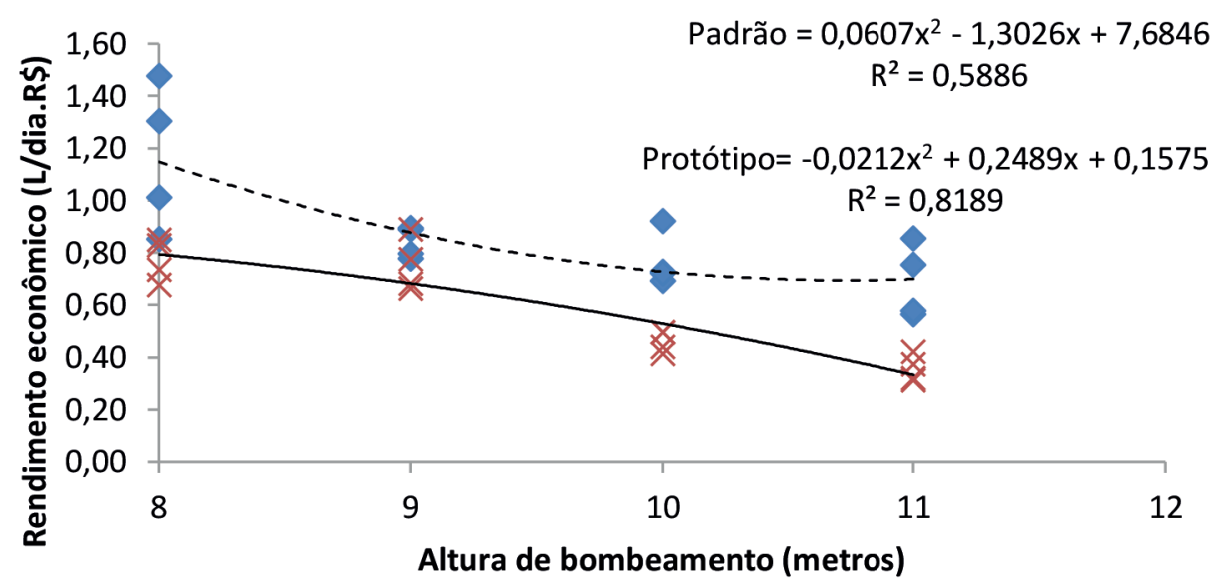

- Padrao $\times$ Prototipo ---- Polinomial (Padrao) - Polinomial (Prototipo)

Fonte: Elaborada pelos autores (2017). 


\title{
Conclusão
}

Para as condições avaliadas conclui-se que a inclusão de uma válvula de retenção no carneiro protótipo não gera aumento de rendimento em altura de bombeamento assim como não há o aumento de pressão interna ou variações no funcionamento que levassem à ocorrência de danos mecânicos ou vazamentos no equipamento.

O aumento de aproximadamente $\mathrm{R} \$ 53,00$ para a construção do protótipo não resultou no aumento de rendimento do sistema, prejudicando a relação custo-benefício para as condições avaliadas.

A regulagem no número de batidas por minuto deve ser específica para cada equipamento para obtenção do melhor rendimento. Assim, recomenda-se buscar a regulagem adequada para que cada equipamento trabalhe dentro da sua faixa de máxima eficiência.

\section{Pumping yield of a PVC hydraulic ram prototype}

\begin{abstract}
The use of hydraulic rams has increased due to energy problems in rural environments and to the need for irrigation of crops, even in small properties. These pumps work on the principle of water hammer to pump water without the use of external energy; however, they present low efficiency, considering the pumping yield as a function of the pumping height. Thus, the objective of the present study was to evaluate the efficiency gain of a hydraulic ram through the addition of pressure retaining valve at its inlet. The valve has the function of forming a physical barrier to the water that returns after the blowing with the suction valve. The prototype was tested using a randomized block design, with 4 blocks. A conventional PVC hydraulic ram and a hydraulic ram with a pressure retaining valve were installed and evaluated at the same time and with the same pumping height, which increased one meter every four days, with four replications for each height. The water output flow, system inlet and outlet pressure, inlet flow, pumped water volume, and number of beats per minute were evaluated to assess the efficiency of the hydraulic ram prototype. The hydraulic ram with the valve presented lower pumping yields in most evaluated heights; it presented better pumping than the conventional hydraulic ham only for the height of nine meters, denoting a poor cost/benefit ratio.
\end{abstract}

Keywords: Water hammer. Pumping efficiency. Retention valve.

\section{Referências}

ABATE, C.; BOTREL, T. A. Avaliação do desempenho de um carneiro hidráulico com tubulação de alimentação em aço galvanizado e PVC. Scientia Agricola, Piracicaba, v. 59, n. 1, p. 197-203. Disponível em: http://www.scielo.br/pdf/sa/v59n1/8095.pdf Acesso em: 12 abr. 2017.

AZEVEdO NETO, J. M.; FERNANDEZ, M. F.; ARAÚJO, R.; ITO, A. E. Manual de hidráulica. Capítulos A11 e A12 8. ed. São Paulo. Ed.Edgard Blücher, 1998.225-308p. 
CARVALHO, J. A.; OLIVEIRA, L. F. C. de.In:_Instalações de bombeamento para irrigação. Lavras/ MG: Editora UFLA, 2008.Capitulo 25, 347-362p.

CARARO, D. C.; DAMASCENO, F. A.; GRIFFANTE, G.; ALVARENGA, L. A. Caracterísitcas construtivas de um carneiro hidráulico com materiais alternativos. Revista Brasileira de Engenharia Agrícola e Ambiental, Campinas Grande, v. 11, n. 4, p. 349-354, 2007.

FERREIRA, D. F. Sisvar: a Guide for its Bootstrap procedures in multiple comparisons. Ciência e Agrotecnologia, Lavras, v. 38, n. 2, p. 109-112, 2014. Disponível em: http://dx.doi.org/10. 1590/ S1413-70542014000200001. Acesso em:12 abr. 2017.

COMO fazer um carneiro hidráulico. Revista Globo Rural, Rio de Janeiro, p. 1, maio, 2015. Disponível em: http://revistagloborural.globo.com/vida-na-fazenda/noticia/2015/05/como-fazer-o-carneiro-hidraulico.html. Acesso em: 20 maio 2016.

TIAGO FILHO, G. L. Carneiro Hidráulico: o que é e como produzi-lo. Itajubá : Centro Nacional de Referência em Pequenos Aproveitamentos Hidro energéticos, 2002. 8p. Disponível em: https://www. slideshare.net/CelsoFerreiradePaula/carneiro-hidraulico-56859971 Acesso em:12 abr. 2017.

WATT, S. B. A manual on the hydraulic ram for pumping water. In: Introdução Londres: Intermediate technology. 1975. p.6

\section{Histórico editorial:}

Submetido em: 27/08/2017

Aceito em: 13/12/2017 